\title{
Does Birthweight Represent Imprinting for Life? Preliminary Findings from the Level and Timing of Diabetic Hyperglycemia in Utero: Transgenerational Effect on Adult Morbidity (TEAM) Study
}

\author{
Jane C. Khoury 1,2,3,*D, Mekibib Altaye 1,2, Shelley Ehrlich 1,2, Suzanne Summer ${ }^{4}$, \\ Nicholas J. Ollberding 1,2, Rhonda Szczesniak ${ }^{1,2}$, Resmi Gupta ${ }^{5}$, Patrick Catalano 6 \\ and Katherine Bowers ${ }^{1,2}$ \\ 1 Division of Biostatistics and Epidemiology, Cincinnati Children's Hospital Medical Center, \\ Cincinnati, OH 45229, USA; Mekibib.Altaye@cchmc.org (M.A.); Shelley.Ehrlich@cchmc.org (S.E.); \\ Nicholas.Ollberding@cchmc.org (N.J.O.); Rhonda.Szczesniak@cchmc.org (R.S.); \\ Katherine.Bowers@cchmc.org (K.B.) \\ 2 Department of Pediatrics, University of Cincinnati College of Medicine, Cincinnati, OH 45267, USA \\ 3 Division of Endocrinology, Cincinnati, Cincinnati Children's Hospital Medical Center, \\ Cincinnati, OH 45229, USA \\ 4 Center for Clinical and Translational Science and Training, Cincinnati Children's Hospital Medical Center, \\ Cincinnati, OH 45229, USA; Suzanne.Summer@cchmc.org \\ 5 Department of Internal Medicine, Division of Clinical and Translational Sciences, McGovern Medical School, \\ The University of Texas at Houston, Houston, TX 77030, USA; Resmi.Gupta@uth.tmc.edu \\ 6 Mother Infant Research Institute, Department of Obstetrics and Gynecology, Friedman School of Nutrition, \\ Science and Policy, Tufts University School of Medicine, Boston, MA 02111, USA; \\ pcatalano@tuftsmedicalcenter.org \\ * Correspondence: Jane.Khoury@cchmc.org; Tel.: +1-513-636-3690
}

Received: 4 November 2020; Accepted: 10 December 2020; Published: 13 December 2020

check for updates

\begin{abstract}
Women with pre-gestational diabetes have a high rate of large for gestational age (LGA) babies compared to women without diabetes. In particular, there is a high rate of asymmetric LGA defined as ponderal index $(\mathrm{PI})>90$ th percentile for gestational age. We examined the association of birth weight and PI, with body mass index (BMI) and obesity status in adulthood, in a cohort of offspring of women with pre-gestational diabetes. The women participated in the Diabetes in Pregnancy (DiP) study at the University of Cincinnati from 1978 to 1995 . The offspring of these women are the cohort participating in an observational study being conducted at Cincinnati Children's Hospital Medical Center. Once located, the offspring were invited to come in for a one-day clinic visit to assess anthropometrics, and their metabolic, renal and cardiovascular status. Linear and logistic regression was used to assess the association between birth weight and PI with current BMI. We report on 107 offspring. A statistically significant association was found between offspring current BMI with birth PI ( $\beta=1.89,95 \% \mathrm{CI} 0.40-3.38)$, and between offspring current obesity status and birth asymmetric LGA $(\mathrm{aOR}=2.44,95 \%$ CI 1.01-5.82). This is consistent with in utero "metabolic programming".
\end{abstract}

Keywords: birthweight; ponderal index; asymmetric large for gestational age; offspring; pre-gestational diabetes; body mass index

\section{Introduction}

For those with pre-gestational diabetes, the associated exacerbations and fluctuations of glucose in utero have been shown to be independently associated with infant birthweight [1]. The resulting 
effect is that the developing fetus gains excess weight and becomes large for gestational age (LGA) by delivery, where LGA is defined as greater than the 90th percentile for gestational age at delivery, race and sex according to specified standards. Despite the exponential improvements in diabetes control in recent decades, the rate of LGA babies born to women with pre-gestational diabetes has not decreased [2,3]. This apparent paradox may be due to the increased insulin taken to aid glycemic control in the mother, which then crosses the placenta and acts as a growth factor for the fetus [4]. In addition, the maternal glucose crossing the placenta also acts as a growth factor by stimulating the production of fetal insulin via the fetal pancreas, which is active as early as 20 weeks' gestation $[5,6]$. We and others have demonstrated that this "fat" baby is also subject to increased risk for other morbidities at delivery, such as hypoglycemia, hyperbilirubinemia and acidosis $[7,8]$, where this "fat" baby is defined as asymmetrically LGA, i.e., LGA for weight but not LGA for length, or LGA for ponderal index (PI) $\left(100 \times\right.$ birthweight $(\mathrm{g}) /$ birth length $\left.(\mathrm{cm})^{3}\right)$.

Barker showed in his seminal work in England that babies small at birth were at increased risk for heart disease in adulthood as well as having a higher rate of obesity than the general population $[9,10]$. This propensity for obesity in adulthood has also been shown in babies of high birthweight [11]. We sought to examine this phenomenon in the young adult offspring of women with pre-gestational diabetes who were at excess risk of being LGA for weight at birth, but were also at excess risk of being asymmetrically LGA, as defined above $[7,12]$. Leveraging data from an ongoing observational study, we examined preliminary outcome data describing the obesity status from our first 107 study participants who were young adult offspring of women who participated in the Diabetes in Pregnancy (DiP) study between 1978 and 1995. All of these women had pre-gestational, type 1 or type 2 diabetes. Detailed pregnancy information is available for these women from the DiP study [13]. For the current analysis, the mothers of all offspring had type 1 diabetes mellitus.

We hypothesized that those babies born with a higher birthweight, or LGA status for birthweight, in particular those with a higher PI or asymmetrical LGA, defined as a PI > 90th percentile for their gestational age, would be overweight or obese as a young adult. The "Level and timing of diabetic hyperglycemia in utero: Transgenerational Effect on Adult Morbidity (TEAM) Study" was approved by the Cincinnati Children's Hospital Medical Center (CCHMC) Institutional Review Board (IRB). The IRB at the University of Cincinnati approved the original DiP study. Informed patient consent was obtained prior to the enrollment of each participant.

\section{Methods}

The TEAM study population was drawn from a total of 454 offspring of women with pre-gestational diabetes who participated in the 17 year NICHD-funded DiP. The DiP study examined the effect of the level of maternal diabetic control on major congenital malformations in offspring. Women were enrolled prior to 9 completed weeks of gestation and were randomized into either strict glucose control or customary control. Those enrolled in the study after 9 completed weeks of gestation or declining randomization were treated as those in the customary control group. For the strict control group, targets for fasting blood glucose and $90 \mathrm{~min}$ post-prandial were: $<100 \mathrm{mg} / \mathrm{dL}$ and $<120 \mathrm{mg} / \mathrm{dL}$, respectively; and for customary glycemic control: $<120 \mathrm{mg} / \mathrm{dL}$ and $<140 \mathrm{mg} / \mathrm{dL}$, respectively [13,14]. Throughout the study, pre-prandial and $90 \mathrm{~min}$ post-prandial blood glucose concentrations of the participants were measured at each clinic visit. After 1981, reflectance meters (Ames Dextrometer; Miles Inc., Diagnostics Division, Elkhart, IN, USA) were implemented in order for the women to self-monitor their glucose levels four to six times daily. Between 1978 and 1980, glycohemoglobin $\mathrm{A}_{1}\left(\mathrm{HbA}_{1}\right)$ concentration was measured by high performance liquid chromatography as the sum of $\mathrm{HbA}_{1 \mathrm{c}}$ and $\mathrm{HbA}_{1 \mathrm{a}+\mathrm{b}}$; normal range 5-9\% [15]. From 1981 until the end of the study, the $\mathrm{HbA}_{1}$ concentration was measured using anion exchange column chromatography; normal range 5.5-8.5\% [16]. The concentration of maternal $\mathrm{HbA}_{1}$ was measured monthly. Due to the multiple methods and the current use of $\mathrm{HbA}_{1 \mathrm{c}}$, the maternal $\mathrm{HbA}_{1}$ concentration was reported as the standard deviation from the mean. Weekly clinic visits were initiated at randomization for the strict control group and at the beginning of the second trimester 
for the customary control group, preceded by visits every two weeks prior to that point. Clinic visits included consultation with the nurse educator, a maternal-fetal specialist and endocrinologist; study measures included weight, blood pressure, complete blood count and urinalysis and glucose levels were discussed with the diabetes care provider. More details regarding the visits have been published elsewhere [13]. Gestational age was determined using last menstrual period (LMP), confirmed by ultrasound. The birthweight of the offspring was measured to the nearest gram using an electronic scale within one hour of delivery (Toledo Scale, Worthington, OH, USA). Birth length was measured to the nearest centimeter using a tape placed beneath the infant as the distance between the vertex of the head and the base of the heel; the infant was placed on a flat surface with legs fully extended for measurement. Large for gestational age (LGA) was defined as $>90$ th percentile for gestational age and sex for birthweight [17], and for gestational age for length and ponderal index [18]. Ponderal index (PI) is defined as $100 \times$ birthweight $(\mathrm{g}) /$ birth length $(\mathrm{cm})^{3}$ and is used to assess asymmetry of growth [12].

The TEAM Study aims to enroll 250 offspring of the potential 454 eligible from the DiP Study. The order of contact for 435 of the offspring was randomized to obtain an unbiased order of recruitment. A total of 19 of the offspring had participated in a pilot study in 2008 and so were targeted for inclusion in the current study and included in the first contact sample. As only the mother's name and mother and offspring dates of birth were known, multiple methods were employed to enable the location and recruitment of the offspring. These included the potential contact of both the mother and the offspring using CCHMC electronic medical records, Accurint LexusNexus (accurint.com), fastpeoplesearch.com, familytreenow.com and public records. Once potential participants were identified, letters of introduction were sent, which included an opt-out return sheet and a contact phone number. After six weeks, phone or email contact was attempted under pre-specified guidelines. Recruitment began in March 2018 and 107 study subjects had successfully completed visits prior to the March 2020, COVID-19 shutdown. Study visits resumed in September 2020 and are ongoing.

The TEAM Study visit includes anthropometric measurements, blood pressure, cardiovascular tests of structure and function, metabolic and renal laboratory measures, oral glucose tolerance test, questionnaires of health history, physical activity and sleep, $24 \mathrm{~h}$ food recall and food frequency, and dual energy X-ray absorptiometry. For this analysis, we utilized the anthropometric measurements of weight and height to calculate the body mass index (BMI). Standing height, to the nearest 0.1 centimeter $(\mathrm{cm})$, was measured by trained clinical research personnel using a calibrated wall-mounted stadiometer (Holtain Harpenden, Holtain Ltd, Crymych, UK). Body weight was determined using a calibrated digital adult stand-on scale (Scaletronix 5002, Hill-Rom Inc, Chicago, IL) and recorded to the nearest 0.1 kilogram $(\mathrm{kg})$. Subjects were weighed after voiding, with shoes and outer clothing layers removed. All measurements were obtained in duplicate, with a third measurement performed if a predefined discrepancy occurred. BMI was calculated as weight $(\mathrm{kg}) /$ height $(\mathrm{m})^{2}$, and obesity class was defined as underweight: $\mathrm{BMI}<18.5$; normal: $18.5<\mathrm{BMI}<25$; overweight: $25 \leq \mathrm{BMI}<30$; obesity Class I: $30 \leq$ BMI < 35; obesity Class II: $35 \leq$ BMI < 40; obesity Class III: BMI $\geq 40$. For analysis purposes, underweight and normal were collapsed, and obesity Classes II and III were collapsed. Visit data for the TEAM Study were entered into a REDCap ${ }^{\circledR}$ database, version 10.0.15 (hosted at the University of Cincinnati and Cincinnati Children's Hospital Medical Center).

\section{Statistical Analysis}

Data were managed and analyzed using SAS ${ }^{\circledR}$, version 9.4 (SAS Institute, Cary, NC, USA). Initially, the frequencies and distributions of variables were examined, to look for outliers and potential errant values. Association between the outcome variables, independent variables of interest and potential covariates were assessed using chi-square, analysis of variance or correlation as appropriate.

The outcomes of interest were BMI as a continuous variable, and obesity class as measured at the TEAM Study visit. The independent variables of interest were birthweight as a continuous variable, and LGA for birthweight as defined by birthweight for gestation >90th percentile, and PI at birth, LGA for asymmetry as defined by ponderal index $>90$ th percentile. Association between the BMI 
of the offspring at the TEAM Study visit and the independent variables of interest were examined using linear regression, while ordinal logistic regression was used for examining the obesity class (normal, overweight, obese I and obese II/III) as the outcome. Further analysis examining obesity classes II/III versus not obese II/III was performed using logistic regression. Maternal covariates considered in the analyses were: maternal age at LMP for the pregnancy, maternal age at diagnosis of diabetes, number of years since diagnosis of diabetes at LMP, presence of microvascular disease (retinopathy or nephropathy), parity, gravida, weight and BMI at LMP, weight gain over pregnancy, diabetes control (mean $\mathrm{HbA}_{1}$ ), development of preeclampsia during pregnancy and gestational age at delivery. Covariates were considered for inclusion in the initial model if bi-variately associated with the outcome or independent variable of interest at $p<0.20$. All other associations were considered statistically significant at $p<0.05$. We are missing five birthweights and 13 birth lengths on the neonates, and we are currently in the process of requesting records to obtain these values. For the available data, we conducted additional sensitivity analysis by imputing the missing data using multiple imputation methods [19]. Briefly, we obtained estimates of regression coefficients by creating 20 imputed data sets with imputations drawn from an underlying distribution of the observed data to estimate the multiple values that reflect the uncertainty around the true value of the missing variables. This was conducted using the SAS procedure PROC MIAnalyze.

\section{Results}

Outcome data from 107 follow-up visits were available for analysis. At follow-up, the offspring were mean age the 32.0 years (standard deviation (sd): 4.42 years), $48 \%$ were female and $13 \%$ were black. They had a mean BMI of $32.1 \mathrm{~kg} / \mathrm{m}^{2}$ (sd: $8.49 \mathrm{~kg} / \mathrm{m}^{2}$ ), distributed as $21 \%$ normal weight, $24 \%$ overweight, $28 \%$ obesity class I and $27 \%$ obesity class II or III. At birth the offspring had a mean weight of $3345 \mathrm{~g}$ (sd: $771 \mathrm{~g}$ ), PI $2.96 \mathrm{~g} / \mathrm{cm}^{3}$ (sd: $1.08 \mathrm{~g} / \mathrm{cm}^{3}$ ), and 27\% were asymmetric LGA and 49\% LGA for weight. At LMP the mothers were on average 26.1 years (sd: 4.60 years) and had been diagnosed with diabetes at 13.8 years of age (sd: 6.44 years). Their weight at LMP was $63.0 \mathrm{~kg}$ (sd: $11.8 \mathrm{~kg}$ ), with associated BMI $23.5 \mathrm{~kg} / \mathrm{m}^{2}$ (sd: $3.72 \mathrm{~kg} / \mathrm{m}^{2}$ ), distributed as $74 \%$ normal or underweight, $21 \%$ overweight and 4\% obesity class I. Weight gain over pregnancy was on average $15.0 \mathrm{~kg}$ (sd: $5.40 \mathrm{~kg}$ ). Selected maternal and offspring characteristics by offspring obesity status are shown in Table 1 and by birthweight LGA and ponderal index LGA in Table 2.

Table 1. Maternal and offspring characteristics and their association with later offspring obesity class 22-40 years after delivery.

\begin{tabular}{|c|c|c|c|c|c|}
\hline Obesity Status & Normal & Overweight & Obese 1 & Obese $2+$ & $p$-Value \\
\hline BMI & $<25 \mathrm{~kg} / \mathrm{m}^{2}$ & 25 to $<30 \mathrm{~kg} / \mathrm{m}^{2}$ & 30 to $<35 \mathrm{~kg} / \mathrm{m}^{2}$ & $\geq 35 \mathrm{~kg} / \mathrm{m}^{2}$ & \\
\hline $\mathrm{N}$ & 22 & 26 & 30 & 29 & \\
\hline \multicolumn{6}{|c|}{ Maternal Characteristics } \\
\hline Age at LMP (y) & $28.7(4.02)$ & $25.8(3.31)$ & $25.1(4.57)$ & $25.4(5.43)$ & 0.03 \\
\hline Age at Dx diabetes $(y)$ & $14.9(5.30)$ & $11.8(6.33)$ & $15.2(7.08)$ & $13.4(6.66)$ & 0.21 \\
\hline Years since Dx diabetes $(y)$ & $13.8(6.40)$ & $14.0(7.02)$ & $9.9(6.23)$ & $12.0(5.92)$ & 0.07 \\
\hline Microvascular disease & $7(31.8 \%)$ & $6(25.0 \%)$ & $3(10.0 \%)$ & $932.1 \%)$ & 0.17 \\
\hline Primaparous (parity $=0$ ) & $9(40.9 \%)$ & $11(45.8 \%)$ & $18(60.0 \%)$ & $16(57.1 \%)$ & 0.47 \\
\hline Primagravida (gravida $=1$ ) & $8(36.4 \%)$ & $9(37.5 \%)$ & $14(46.7 \%)$ & $10(35.7 \%)$ & 0.81 \\
\hline Weight at LMP (kg) & $60.8(7.2)$ & $59.0(12.8)$ & $62.8(11.1)$ & $68.6(13.0)$ & 0.02 \\
\hline BMI at $\mathrm{LMP}\left(\mathrm{kg} / \mathrm{m}^{2}\right)$ & $22.6(2.29)$ & $22.6(4.00)$ & $22.9(3.25)$ & $25.2(4.43)$ & 0.03 \\
\hline \multicolumn{6}{|l|}{ Obesity class at LMP } \\
\hline$<25 \mathrm{~kg} / \mathrm{m}^{2}$ & $19(90.5 \%)$ & $18(81.8 \%)$ & $22(73.3 \%)$ & $15(57.7 \%)$ & \multirow{3}{*}{0.26} \\
\hline $25-<30 \mathrm{~kg} / \mathrm{m}^{2}$ & $2(9.5 \%)$ & $3(13.6 \%)$ & $7(23.2 \%)$ & $9(34.6 \%)$ & \\
\hline $30-<35 \mathrm{~kg} / \mathrm{m}^{2}$ & 0 & $1(4.6 \%)$ & $1(3.3 \%)$ & $2(7.7 \%)$ & \\
\hline
\end{tabular}


Table 1. Cont

\begin{tabular}{|c|c|c|c|c|c|}
\hline Obesity Status & Normal & Overweight & Obese 1 & Obese $2+$ & $p$-Value \\
\hline BMI & $<25 \mathrm{~kg} / \mathrm{m}^{2}$ & 25 to $<30 \mathrm{~kg} / \mathrm{m}^{2}$ & 30 to $<35 \mathrm{~kg} / \mathrm{m}^{2}$ & $\geq 35 \mathrm{~kg} / \mathrm{m}^{2}$ & \\
\hline $\mathrm{N}$ & 22 & 26 & 30 & 29 & \\
\hline \multicolumn{6}{|c|}{ Maternal Characteristics } \\
\hline $\begin{array}{l}\text { Mean } \mathrm{HbA}_{1} \text { over } \\
\text { pregnancy }(\mathrm{sd})\end{array}$ & $1.96(1.44)$ & $1.74(1.78)$ & $2.10(1.34)$ & $1.96(1.84)$ & 0.88 \\
\hline Preeclampsia & $3(14.3 \%)$ & $2(8.7 \%)$ & $4(14.3 \%)$ & $4(15.4 \%)$ & 0.91 \\
\hline $\begin{array}{l}\text { Gestation at delivery } \\
\text { (weeks) }\end{array}$ & $35.6(3.82)$ & $37.1(2.07)$ & $37.3(2.20)$ & $37.4(1.72)$ & 0.06 \\
\hline Pregnancy weight gain (kg) & $12.2(5.37)$ & $14.6(3.43)$ & $15.7(6.54)$ & $16.8(4.65)$ & 0.02 \\
\hline \multicolumn{6}{|c|}{ Offspring Characteristics } \\
\hline Birthweight (g) & 3231 (1059) & $3283(702)$ & $3466(639)$ & $3353(727)$ & 0.72 \\
\hline $\begin{array}{l}\text { Birthweight }>90 \text { th } \\
\text { percentile }\end{array}$ & $10(47.6 \%)$ & $10(43.5 \%)$ & $17(56.7 \%)$ & $13(46.4 \%)$ & 0.78 \\
\hline Birth length $(\mathrm{cm})$ & $48.3(5.99)$ & $48.3(3.54)$ & 49.9 (3.17) & $48.1(4.46)$ & 0.92 \\
\hline $\begin{array}{l}\text { Birth length }>90 \text { th } \\
\text { percentile }\end{array}$ & $5(29.4 \%)$ & $3(13.6 \%)$ & $5(17.9 \%)$ & $2(7.4 \%)$ & 0.27 \\
\hline Ponderal index $\mathrm{g} / \mathrm{cm}^{3}$ & $2.74(0.59)$ & $2.85(0.22)$ & $2.91(0.29)$ & $3.22(1.93)$ & 0.47 \\
\hline $\begin{array}{c}\text { Ponderal index }>90 \text { th } \\
\text { percentile }\end{array}$ & $2(11.8 \%)$ & $5(22.7 \%)$ & $7(25.0 \%)$ & $11(40.7 \%)$ & 0.18 \\
\hline Age at follow-up visit (y) & $31.2(4.22)$ & $31.9(5.05)$ & $32.8(4.36)$ & $31.7(4.10$ & 0.58 \\
\hline Sex (female) & $14(63.6 \%)$ & $10(38.5 \%)$ & $14(46.7 \%)$ & $13(44.8 \%)$ & 0.36 \\
\hline Race (black) & $1(4.6 \%)$ & $3(11.5 \%)$ & $5(16.7 \%)$ & $5(17.2 \%)$ & 0.52 \\
\hline Ever smoked & $15(68.2 \%)$ & $15(57.7 \%)$ & $24(80.0)$ & $18(62.1 \%)$ & 0.30 \\
\hline Smoked in past 30 days & $7(31.8 \%)$ & $3(11.5 \%)$ & $6(20.0 \%)$ & $5(17.2 \%)$ & 0.35 \\
\hline
\end{tabular}

Data presented as the mean (standard deviation or $\mathrm{n}$ (percentage), BMI is body mass index, LMP is the last menstrual period, glycohemoglobin $\mathrm{A}_{1}\left(\mathrm{HbA}_{1}\right)$ is expressed as number of standard deviations (sd) from the mean.

Table 2. Maternal and offspring characteristics and their association with offspring large for gestational age (LGA) status at birth.

\begin{tabular}{ccccccc}
\hline Obesity Status & \multicolumn{2}{c}{ Birth Weight } & $p$-Value & \multicolumn{2}{c}{ Ponderal Index } & $p$-Value \\
\hline BMI & LGA & Not LGA & LGA & Not LGA \\
\hline N & 50 & 52 & 25 & 69 \\
\hline \multicolumn{7}{c}{ Maternal Characteristics } \\
\hline Age at LMP $(\mathrm{y})$ & $25.5(4.70)$ & $26.6(4.54)$ & 0.24 & $25.4(5.33)$ & $26.2(4.24)$ & 0.47 \\
\hline Age at Dx diabetes $(\mathrm{y})$ & $14.9(7.06)$ & $13.0(5.86)$ & 0.14 & $12.7(7.58)$ & $14.2(6.27)$ & 0.32 \\
\hline Years since Dx diabetes $(\mathrm{y})$ & $10.6(6.40)$ & $13.6(6.54)$ & 0.02 & $12.8(6.86)$ & $12.0(6.34)$ & 0.62 \\
\hline Microvascular disease & $6(10.0 \%)$ & $19(36.5 \%)$ & 0.002 & $9(36.0 \%)$ & $14(20.3 \%)$ & 0.12 \\
\hline Primaparous (parity =0) & $24(46.0 \%)$ & $29(55.8 \%)$ & 0.43 & $16(64.0 \%)$ & $32(46.4 \%)$ & 0.13 \\
\hline $\begin{array}{c}\text { Primagravida } \\
\text { gravida }=1)\end{array}$ & $20(40.0 \%)$ & $20(38.5 \%)$ & 0.87 & $12(48.0 \%)$ & $23(33.3 \%)$ & 0.19 \\
\hline Weight at LMP $(\mathrm{kg})$ & $65.3(13.7)$ & $60.9(9.36)$ & 0.06 & $67.3(15.1)$ & $61.6(10.7)$ & 0.09 \\
\hline BMI at LMP $\left(\mathrm{kg} / \mathrm{m}^{2}\right)$ & $23.8(4.12)$ & $22.9(3.24)$ & 0.22 & $24.6(4.57)$ & $23.1(3.41)$ & 0.09 \\
\hline
\end{tabular}


Table 2. Cont.

\begin{tabular}{|c|c|c|c|c|c|c|}
\hline \multirow{2}{*}{$\begin{array}{c}\text { Obesity Status } \\
\text { BMI }\end{array}$} & \multicolumn{2}{|c|}{ Birth Weight } & \multirow[t]{2}{*}{$p$-Value } & \multicolumn{2}{|c|}{ Ponderal Index } & \multirow[t]{2}{*}{$p$-Value } \\
\hline & LGA & Not LGA & & LGA & Not LGA & \\
\hline $\mathrm{N}$ & 50 & 52 & & 25 & 69 & \\
\hline \multicolumn{7}{|c|}{ Maternal Characteristics } \\
\hline $\begin{array}{c}\text { Obesity Class at LMP } \\
<25 \mathrm{~kg} / \mathrm{m}^{2} \\
25-<30 \mathrm{~kg} / \mathrm{m}^{2} \\
30-<35 \mathrm{~kg} / \mathrm{m}^{2}\end{array}$ & $\begin{array}{c}34(68.0 \%) \\
13(26.0 \%) \\
3(6.0 \%)\end{array}$ & $\begin{array}{c}40(81.6 \%) \\
8(16.3 \%) \\
1(2.0 \%) \\
\end{array}$ & 0.32 & $\begin{array}{c}16(64.0 \%) \\
7(28.0 \%) \\
2(8.0 \%) \\
\end{array}$ & $\begin{array}{c}52(78.8 \%) \\
12(18.2 \%) \\
2(3.0 \%) \\
\end{array}$ & 0.44 \\
\hline $\begin{array}{l}\text { Pregnancy weight gain } \\
(\mathrm{kg})\end{array}$ & $16.4(5.53)$ & $13.7(4.86)$ & 0.01 & $17.7(5.28)$ & $14.0(5.10)$ & 0.003 \\
\hline $\begin{array}{l}\text { Mean } \mathrm{HbA}_{1} \text { over } \\
\text { pregnancy }(\mathrm{sd})\end{array}$ & $2.03(1.74)$ & $1.91(1.47)$ & 0.70 & $2.35(2.16)$ & $1.77(1.31)$ & 0.12 \\
\hline Preeclampsia & $2(4.0 \%$ & $11(22.0 \%)$ & 0.01 & $4(16.0 \%)$ & $8(11.9 \%)$ & 0.61 \\
\hline $\begin{array}{l}\text { Gestational age at delivery } \\
\text { (weeks) }\end{array}$ & $37.6(1.62)$ & $36.4(3.00)$ & 0.02 & $37.2(2.17)$ & $36.9(2.45)$ & 0.60 \\
\hline
\end{tabular}

\begin{tabular}{ccccccc}
\hline \multicolumn{7}{c}{ Offspring Characteristics } \\
\hline Age at follow-up visit (y) & $32.4(4.04)$ & $32.3(4.32)$ & 0.73 & $32.9(3.49)$ & $32.4(4.29)$ & 0.85 \\
\hline Sex (female) & $24(48.0 \%)$ & $25(48.1 \%)$ & 0.99 & $11(44.0 \%)$ & $32(46.4 \%)$ & 0.84 \\
\hline Race (black) & $6(12.0 \%)$ & $8(15.4 \%)$ & 0.62 & $5(20.0 \%)$ & $9(13.0 \%)$ & 0.40 \\
\hline Ever smoked & $34(68.0 \%)$ & $36(69.2 \%)$ & 0.89 & $15(60.0 \%)$ & $51(73.9 \%)$ & 0.19 \\
\hline Smoked in past 30 days & $8(16.0 \%)$ & $12(23.1 \%)$ & 0.37 & $4(16.0 \%)$ & $15(21.7 \%)$ & 0.54 \\
\hline
\end{tabular}

Data presented as the mean (standard deviation or $n$ (percentage), LMP is the last menstrual period, Glycohemoglobin $\mathrm{A}_{1}\left(\mathrm{HbA}_{1}\right)$ is expressed as number of standard deviations (sd) from the mean LGA is large for gestational age (>90th percentile).

The initial models assessing the association between the outcome variables' offspring BMI and obesity status, and the independent variables birthweight and LGA for birthweight included the following covariates: maternal age at LMP, years since diagnosis of diabetes, microvascular disease, BMI at LMP, weight gain over pregnancy, preeclampsia and gestational age at delivery (for birthweight only). The initial models assessing PI and asymmetric LGA in the infant as the independent variables of interest, included: maternal age at LMP, years since diagnosis of diabetes, microvascular disease, primiparity, BMI at LMP, weight gain over pregnancy, mean $\mathrm{HBA}_{1}$ over pregnancy, and gestational age at delivery (for PI only) as covariates. The beta coefficients and adjusted odds ratios for the independent variables birthweight, LGA for birthweight, PI and asymmetric LGA in the final models are shown in Table 3. The associations of PI with offspring BMI ( $\beta=1.89,95 \%$ CI $0.40-3.38$, per unit of PI) and of LGA for PI with obesity class (aOR 2.44, 95\% CI 1.01-5.82) are statistically significant, and the associations of LGA for PI with both BMI and obesity are trending to significance. BMI at LMP is an important factor in all the models, and weight gain over pregnancy is important in most of the models. The covariates presence of microvascular disease and years since diagnosis of diabetes are also significant in some of the models. Gestational age at delivery was kept in the model, regardless of the statistical significance, when examining birthweight as the independent variable of interest. The imputed data analysis produced comparable and consistent results with our main analysis. 
Table 3. Results from regression, ordinal logistic regression and logistic regression showing the association of the independent variables of interest and the outcome variables.

\begin{tabular}{|c|c|c|c|c|}
\hline \multirow[t]{2}{*}{ Analytic Model } & \multicolumn{4}{|c|}{ Independent Variable of Interest } \\
\hline & $\begin{array}{l}\text { Birthweight } / 100 \\
\text { (g) }\end{array}$ & $\begin{array}{c}\text { LGA for } \\
\text { Birthweight }\end{array}$ & $\begin{array}{l}\text { Ponderal } \\
\text { Index/Unit }\end{array}$ & LGA for PI \\
\hline $\begin{array}{l}\text { Offspring BMI kg/m² } \\
\text { Linear regression }\end{array}$ & $\begin{array}{c}\beta=-0.02^{a} \\
(\text { se }=0.01) \\
(p=0.13)\end{array}$ & $\begin{array}{c}\beta=-0.96^{\mathrm{b}} \\
(\mathrm{se}=1.66) \\
(p=0.56)\end{array}$ & $\begin{array}{l}\beta=1.89^{c} \\
(\mathrm{se}=0.76) \\
(p=0.01)\end{array}$ & $\begin{array}{l}\beta=3.41^{\mathrm{d}} \\
(\mathrm{se}=1.95) \\
(p=0.08)\end{array}$ \\
\hline $\begin{array}{l}\text { Offspring obesity class } \\
\text { Ordinal regression } \\
\text { (normal, overweight, } \\
\text { obesity class I, obesity } \\
\text { class II/III) }\end{array}$ & $\begin{array}{c}\mathrm{aOR}=0.96^{\mathrm{a}} \\
(95 \% \mathrm{CI} \\
0.89,1.03) \\
(p=0.24)\end{array}$ & $\begin{array}{c}\mathrm{aOR}=0.78^{\mathrm{b}} \\
(95 \% \mathrm{CI} \\
0.37,1.63) \\
(p=0.50)\end{array}$ & $\begin{array}{c}\mathrm{aOR}=1.60^{\mathrm{b}} \\
(95 \% \mathrm{CI} \\
0.73,3.50) \\
(p=0.24)\end{array}$ & $\begin{array}{c}\mathrm{aOR}=2.44^{\mathrm{d}} \\
(95 \% \mathrm{CI} \\
1.01,5.82) \\
(p=0.045)\end{array}$ \\
\hline $\begin{array}{l}\text { Offspring obesity class } \\
\text { II/III versus not obesity } \\
\text { class II/III } \\
\text { Logistic regression }\end{array}$ & $\begin{array}{c}\mathrm{aOR}=1.01 \mathrm{e} \\
(95 \% \mathrm{CI} \\
0.91,1.12) \\
(p=0.88)\end{array}$ & $\begin{array}{c}\mathrm{aOR}=0.84^{\mathrm{f}} \\
(95 \% \mathrm{CI} \\
0.28,2.52) \\
(p=0.76)\end{array}$ & $\begin{array}{c}\mathrm{aOR}=2.18^{\mathrm{f}} \\
(95 \% \mathrm{CI} \\
0.76,6.24) \\
(p=0.15)\end{array}$ & $\begin{array}{c}\mathrm{aOR}=2.53^{\mathrm{d}} \\
(95 \% \mathrm{CI} \\
0.91,7.03) \\
(p=0.08)\end{array}$ \\
\hline
\end{tabular}

$\beta$ is the regression coefficient; se is the standard error; aOR is the adjusted odds ratio; $95 \% \mathrm{CI}$ is the $95 \%$ confidence interval. The covariates remaining in the final models are denoted by the superscript shown below: ${ }^{\mathrm{a}}$-adjusting for BMI-LMP, weight gain and gestation at delivery; ${ }^{b}$ - adjusting for BMI-LMP and weight gain; ${ }^{c}$ - adjusting for BMI-LMP, weight gain, years since diagnosis of diabetes and microvascular disease; ${ }^{\mathrm{d}}$-adjusting for BMI-LMP; e - adjusting for BMI-LMP, microvascular disease and gestation at delivery; ${ }^{\mathrm{f}}$-adjusting for BMI-LMP, weight gain and microvascular disease.

\section{Discussion}

We examined the birthweight status in the offspring of women with pre-gestational diabetes and its association with their body weight status at follow up 22-40 years later, in young adulthood. We found, however, that rather than birthweight per se, the distribution of fat as estimated by PI $\left(100\right.$ * weight $(\mathrm{g}) /$ length $\left.(\mathrm{cm})^{3}\right)$ had a stronger association with the current weight status, as defined by BMI, in the offspring. This was after accounting for maternal pre-pregnancy weight and pregnancy weight gain. This phenomenon was not totally surprising due to some early work by our group during the initial DiP study looking at the rate of asymmetric macrosomia in the newborns of women with pre-gestational diabetes and the association with neonatal morbidity [7]. What was surprising was the lack of association with maternal glycemic control during pregnancy. However, this will be further addressed when we have a larger sample size and are able to apply our methods of semiparametric regression and joint modelling using the glucose concentrations from self-glucose monitoring collected over gestation in these mothers, rather than the $\mathrm{HbA}_{1}$ over pregnancy [20-22].

Consistent with other publications we do find that maternal BMI at the beginning of pregnancy and maternal weight gain over pregnancy are important covariates to consider for inclusion in the models [8,23-27]. These factors have been reported as important when assessing both offspring birthweight and weight later in life. For this analysis, we used overall weight gain, but there is still controversy regarding the most important period of the maternal weight gain to consider in relation to birthweight, early, mid or to late pregnancy $[14,28,29]$. The association of the timing of gestational weight gain with respect to offspring BMI later in life is slated for future research in our study.

Of potential interest was the significance of microvascular disease of the mother in some of the models. Although this was purely examined as a covariate, it may be of interest for future study, examining the severity of maternal diabetes as a moderator of glucose control. This association with microvascular disease, albeit as a covariate in the model, suggests that microvascular disease may be associated with a risk for the higher BMI of the offspring in young adulthood. This ties in with the Barker hypothesis, as women with microvascular disease tend to have smaller babies, where these smaller babies, by way of over-nutrition, are likely to have a higher BMI in adulthood [9]. Future exploration of the role of microvascular disease in offspring outcome is warranted. 
The limitation of our study is the sample size, despite which we observed biologically and clinically meaningful findings. The finding that those offspring who have increased BMI previously tended to have a higher PI and weight for length at delivery, rather than just weight at delivery, is appealing, although there has been genetic evidence that birthweight rather than PI is a more important/stronger correlate [30]. It should be noted that we found that not only is the rate of LGA for weight in the neonate born to a woman with pre-gestational diabetes greater than that for a neonate born to a woman without, but the rate of LGA for PI is also increased-at a rate of 19\% [7]. With continued recruitment to obtain a larger sample size, we will be able to expand on this research question, including the role of gestational glycemic control and gestational week(s)-specific weight gain.

Author Contributions: Conceptualization, J.C.K., S.E. and K.B.; methodology, J.C.K., M.A., S.S., N.J.O. and R.S.; formal analysis, J.C.K. and M.A.; drafted the manuscript, J.C.K.; review and editing: J.C.K., K.B., S.E., M.A., S.S., N.J.O., R.S., R.G., P.C. All authors have read and agreed to the published version of the manuscript.

Funding: This research received no external funding.

Acknowledgments: We would like to thank the study subjects for their participation in the TEAM study and their mothers for their participation in the DiP study, without whom we would not be able to do this research. We would also like to thank our dedicated clinical research coordinators, Emily Smith and Sang Sam, who are the heart of the study, finding study subjects, scheduling study visits and ensuring that the visits run smoothly. This TEAM Study grant is funded by NIH NIDDK R01 DK109956, and the Diabetes in Pregnancy Program Project Grant was funded from 1978 to 1995 by NIH NICHD HD11725. This research was also supported in part by an Institutional Clinical and Translational Science Award, NIH/ NCATS grant no. 2UL1TR001425-05A. The content is solely the responsibility of the authors and does not necessarily represent the official views of the NIH.

Conflicts of Interest: The authors declare no conflict of interest.

\section{References}

1. Gupta, R.; Khoury, J.; Altaye, M.; Dolan, L.; Szczesniak, R.D. Glycemic Excursions in Type 1 Diabetes in Pregnancy: A Semiparametric Statistical Approach to Identify Sensitive Time Points during Gestation. J. Diabetes Res. 2017, 2017, 2852913. [CrossRef]

2. McWhorter, K.L.; Bowers, K.; Dolan, L.M.; Deka, R.; Jackson, C.L.; Khoury, J.C. Impact of gestational weight gain and prepregnancy body mass index on the prevalence of large-for-gestational age infants in two cohorts of women with type 1 insulin-dependent diabetes: A cross-sectional population study. BMJ Open 2018, 8, e019617. [CrossRef] [PubMed]

3. Mulla, B.M.; Noor, N.; James-Todd, T.; Isganaitis, E.; Takoudes, T.C.; Curran, A.; Warren, C.E.; O’Brien, K.E.; Brown, F.M. Continuous Glucose Monitoring, Glycemic Variability, and Excessive Fetal Growth in Pregnancies Complicated by Type 1 Diabetes. Diabetes Technol. Ther. 2018, 20, 413-419. [CrossRef] [PubMed]

4. Menon, R.K.; Cohen, R.M.; Sperling, M.A.; Cutfield, W.S.; Mimouni, F.; Khoury, J.C. Transplacental passage of insulin in pregnant women with insulin-dependent diabetes mellitus. Its role in fetal macrosomia. N. Engl. J. Med. 1990, 323, 309-315. [CrossRef]

5. Hay, W.W., Jr. Placental-fetal glucose exchange and fetal glucose metabolism. Trans. Am. Clin. Climatol. Assoc. 2006, 117, 321-339. [PubMed]

6. Dabelea, D. The predisposition to obesity and diabetes in offspring of diabetic mothers. Diabetes Care 2007, 30 (Suppl. 2), S169-S174. [CrossRef]

7. Ballard, J.L.; Rosenn, B.; Khoury, J.C.; Miodovnik, M. Diabetic fetal macrosomia: Significance of disproportionate growth. J. Pediatr. 1993, 122, 115-119. [CrossRef]

8. Kong, L.; Nilsson, I.A.K.; Gissler, M.; Lavebratt, C. Associations of Maternal Diabetes and Body Mass Index With Offspring Birth Weight and Prematurity. JAMA Pediatr. 2019, 173, 371-378. [CrossRef]

9. Barker, D.J. In utero programming of cardiovascular disease. Theriogenology 2000, 53, 555-574. [CrossRef]

10. Dabelea, D.; Pettitt, D.J. Intrauterine diabetic environment confers risks for type 2 diabetes mellitus and obesity in the offspring, in addition to genetic susceptibility. J. Pediatr. Endocrinol. Metab. 2001, 14, 1085-1091. [CrossRef] 
11. Hammoud, N.M.; Visser, G.H.A.; van Rossem, L.; Biesma, D.H.; Wit, J.M.; de Valk, H.W. Long-term BMI and growth profiles in offspring of women with gestational diabetes. Diabetologia 2018, 61, 1037-1045. [CrossRef] [PubMed]

12. Bollepalli, S.; Dolan, L.M.; Miodovnik, M.; Feghali, M.; Khoury, J.C. Asymmetric large-for-gestational-age infants of type 1 diabetic women: Morbidity and abdominal growth. Am. J. Perinatol. 2010, 27, 603-610. [CrossRef] [PubMed]

13. McElvy, S.S.; Miodovnik, M.; Rosenn, B.; Khoury, J.C.; Siddiqi, T.; Dignan, P.S.; Tsang, R.C. A focused preconceptional and early pregnancy program in women with type 1 diabetes reduces perinatal mortality and malformation rates to general population levels. J. Matern. Fetal Med. 2000, 9, 14-20. [CrossRef] [PubMed]

14. Drehmer, M.; Duncan, B.B.; Kac, G.; Schmidt, M.I. Association of second and third trimester weight gain in pregnancy with maternal and fetal outcomes. PLoS ONE 2013, 8, e54704. [CrossRef] [PubMed]

15. Cole, R.A.; Soeldner, J.S.; Dunn, P.J.; Bunn, H.F. A rapid method for the determination of glycosylated hemoglobins using high pressure liquid chromatography. Metabolism 1978, 27, 289-301. [CrossRef]

16. Kaplan, L.A.; Cline, D.; Gartside, P.; Burstein, S.; Sperling, M.; Stein, E.A. Hemoglobin A1 in hemolysates from healthy and insulin-dependent diabetic children, as determined with a temperature-controlled minicolumn assay. Clin. Chem. 1982, 28, 13-18. [CrossRef]

17. Lubchenco, L.O.; Hansman, C.; Dressler, M.; Boyd, E. Intrauterine Growth as Estimated from Liveborn Birth-Weight Data at 24 to 42 Weeks of Gestation. Pediatrics 1963, 32, 793-800.

18. Lubchenco, L.O.; Hansman, C.; Boyd, E. Intrauterine growth in length and head circumference as estimated from live births at gestational ages from 26 to 42 weeks. Pediatrics 1966, 37, 403-408.

19. Little RI, R.D. Statistical Analysis with Missing Data, 2nd ed.; Wiley: New York, NY, USA, 2002.

20. Gupta, R.; Khoury, J.C.; Altaye, M.; Jandarov, R.; Szczesniak, R.D. Assessing the Relationship between Gestational Glycemic Control and Risk of Preterm Birth in Women with Type 1 Diabetes: A Joint Modeling Approach. J. Diabetes Res. 2020, 2020, 3074532. [CrossRef]

21. Vandyke, R.; Ren, Y.; Sucharew, H.J.; Miodovnik, M.; Rosenn, B.; Khoury, J.C. Characterizing maternal glycemic control: A more informative approach using semiparametric regression. J. Matern. Fetal Neonatal. Med. 2012, 25, 15-19. [CrossRef]

22. Szczesniak, R.D.; Li, D.; Duan, L.L.; Altaye, M.; Miodovnik, M.; Khoury, J.C. Longitudinal Patterns of Glycemic Control and Blood Pressure in Pregnant Women with Type 1 Diabetes Mellitus: Phenotypes from Functional Data Analysis. Am. J. Perinatol. 2016, 33, 1282-1290. [CrossRef] [PubMed]

23. Leng, J.; Li, W.; Zhang, S.; Liu, H.; Wang, L.; Liu, G.; Li, N.; Redman, L.M.; Baccarelli, A.A.; Hou, L.; et al. GDM Women's Pre-Pregnancy Overweight/Obesity and Gestational Weight Gain on Offspring Overweight Status. PLoS ONE 2015, 10, e0129536. [CrossRef] [PubMed]

24. Reynolds, R.M.; Osmond, C.; Phillips, D.I.; Godfrey, K.M. Maternal BMI, parity, and pregnancy weight gain: Influences on offspring adiposity in young adulthood. J. Clin. Endocrinol. Metab. 2010, 95, 5365-5369. [CrossRef] [PubMed]

25. Scifres, C.M.; Feghali, M.N.; Althouse, A.D.; Caritis, S.N.; Catov, J.M. Effect of excess gestational weight gain on pregnancy outcomes in women with type 1 diabetes. Obstet. Gynecol. 2014, 123, 1295-1302. [CrossRef] [PubMed]

26. Josefson, J.L.; Catalano, P.M.; Lowe, W.L.; Scholtens, D.M.; Kuang, A.; Dyer, A.R.; Lowe, L.P.; Metzger, B.E. The Joint Associations of Maternal BMI and Glycemia with Childhood Adiposity. J. Clin. Endocrinol. Metab. 2020, 105. [CrossRef]

27. Lowe, W.L., Jr.; Scholtens, D.M.; Lowe, L.P.; Kuang, A.; Nodzenski, M.; Talbot, O.; Catalano, P.M.; Linder, B.; Brickman, W.J.; Clayton, P.; et al. Association of Gestational Diabetes With Maternal Disorders of Glucose Metabolism and Childhood Adiposity. JAMA 2018, 320, 1005-1016. [CrossRef]

28. Broskey, N.T.; Wang, P.; Li, N.; Leng, J.; Li, W.; Wang, L.; Gilmore, L.A.; Hu, G.; Redman, L.M. Early Pregnancy Weight Gain Exerts the Strongest Effect on Birth Weight, Posing a Critical Time to Prevent Childhood Obesity. Obesity 2017, 25, 1569-1576. [CrossRef]

29. Retnakaran, R.; Wen, S.W.; Tan, H.; Zhou, S.; Ye, C.; Shen, M.; Smith, G.N.; Walker, M.C. Association of Timing of Weight Gain in Pregnancy With Infant Birth Weight. JAMA Pediatr. 2018, 172, 136-142. [CrossRef] 
30. Hollensted, M.; Ekstrom, C.T.; Pedersen, O.; Eiberg, H.; Hansen, T.; Gjesing, A.P. Genetic insights into fetal growth and measures of glycaemic regulation and adiposity in adulthood: A family-based study. BMC Med. Genet. 2018, 19, 207. [CrossRef]

Publisher's Note: MDPI stays neutral with regard to jurisdictional claims in published maps and institutional affiliations.

(C) 2020 by the authors. Licensee MDPI, Basel, Switzerland. This article is an open access article distributed under the terms and conditions of the Creative Commons Attribution (CC BY) license (http://creativecommons.org/licenses/by/4.0/). 